\title{
Review
}

\section{The Gut and Parkinson's Disease: Hype or Hope?}

\author{
Filip Scheperjans ${ }^{\mathrm{a}, *}$, Pascal Derkinderen ${ }^{\mathrm{b}}$ and Per Borghammer ${ }^{\mathrm{c}}$ \\ ${ }^{a}$ Department of Neurology, Helsinki University Hospital and Department of Clinical Neurosciences \\ (Neurology), University of Helsinki, Helsinki, Finland \\ ${ }^{\mathrm{b}}$ Department of Neurology, CHU Nantes and Inserm, Nantes, France \\ ${ }^{\mathrm{c}}$ Department of Nuclear Medicine \& PET Centre, Aarhus University Hospital, Aarhus, Denmark
}

Accepted 9 October 2018

\begin{abstract}
In the last two decades it has become clear that Parkinson's disease (PD) is associated with a plethora of gastrointestinal symptoms originating from functional and structural changes in the gut and its associated neural structures. This is of particular interest not only because such symptoms have a major impact on the quality of life of PD patients, but also since accumulating evidence suggests that in at least a subgroup of patients, these disturbances precede the motor symptoms and diagnosis of PD by years and may thus give important insights into the origin and pathogenesis of the disease. In this mini-review we attempt to concisely summarize the current knowledge after two decades of research on the gut-brain axis in PD. We focus on alpha-synuclein pathology, biomarkers, and the gut microbiota and envision the development and impact of these research areas for the two decades to come.
\end{abstract}

Keywords: Alpha-synuclein, prion, constipation, dysautonomia, microbiota, gut-brain-axis

\section{GASTROINTESTINAL PATHOLOGY AND ITS ROLE IN PARKINSON'S DISEASE ETIOLOGY}

The first descriptions of alpha-synuclein (asyn) histopathology in the enteric nervous system (ENS) and peripheral autonomic ganglia date back as far as $1960[1,2]$, and several groups have now confirmed and extended these initial findings [3, 4]. By contrast to the substantia nigra, no overt neuronal loss is observed in the ENS in Parkinson's disease (PD) $[5,6]$. Based on early pathology in the olfactory bulb and dorsal motor nucleus of the vagus, the dual-hit hypothesis posited by Braak and colleagues

\footnotetext{
*Correspondence to: Filip Scheperjans, Department of Neurology, Helsinki University Hospital, Haartmaninkatu 4, FI-00029 Helsinki, Finland. Tel.: +358 9 4711; E-mail: filip.scheperjans@ hus.fi.
}

proposes that initial misfolding and aggregation of asyn may occur in peripheral nerve terminals with subsequent centripetal spreading through the vagus nerve $[7,8]$. This proposition gained support from two epidemiological studies showing that full truncal but not selective vagotomy seems to decrease the risk of PD [9, 10]. Also, in studies of archived tissue removed from patients up to 20 years prior to PD diagnosis, asyn pathology in the gut was reported more frequently than in matched controls [11, 12]. Several animal models, recently reviewed in detail [13], have shown cell-to-cell prion-like transmission and centripetal spreading of asyn [14, 15]. Such studies demonstrate the mechanistic plausibility of gut-to-brain transmission of asyn pathology. Nevertheless, this gut-to-brain transmission hypothesis is still widely debated and the arguments in favor or against the gut as the site of origin of PD were 
reviewed in two recent publications [16, 17]. The strongest argument against such a scenario comes from findings from the Arizona Parkinson's consortium group, which did not find a single case in which asyn pathology was present in the ENS but not in the CNS in their wide survey of 466 whole-body autopsy cases [18]. This whole-body survey does not exclude, however, that initial asyn aggregation may start in the gut, but such hypothetical initial gut pathology would have to be be highly localized, or alternatively consist of immature and potentially protease-sensitive microaggregates, which are difficult to detect by standard immunohistochemistry [16].

In the coming two decades, it is likely that major advances will be made in understanding the role of gastrointestinal asyn pathology in the etiology of PD. An important research goal is to elucidate the degree of similarity between pathophysiological processes in PD and those of true prion diseases. In variant Creutzfeldt-Jakob disease (CJD), there is little doubt about the occurrence of gut-to-brain propagation of prions [19]. The aggregates of disease-related prion protein in variant CJD and bovine spongiform encephalopathy initially form in peripheral lymphoid tissues and in the ENS and then spread through the autonomic nervous system [20, 21]. Importantly, the prion aggregates in peripheral organs of variant CJD show clear differences in glycoform ratios and protease resistance compared to prions in brain tissues $[22,23]$. It has therefore been suggested that the long latency between peripheral lymphoid colonization and subsequent neuro-invasion is in part due to the need for selection of a neuro-invasive strain of prion [24]. Such mechanisms have not been considered in the context of PD, but may explain why asyn multimers or aggregates harvested in peripheral autonomic nervous tissues behave differently than those from the substantia nigra of PD patients $[25,26]$.

There is therefore an urgent need to better characterize the biochemical characteristics of both native and pathological asyn in the ENS (Fig. 1). This can best be achieved by performing a comprehensive inventory of synuclein forms present in the ENS from PD patients using two-dimensional electrophoretic analysis and mass spectroscopy or luminescent conjugated oligothiopenes, as such approaches have proven successful for characterizing the dominant pathological modification of synuclein and amyloids in the brain $[27,28]$. Also, much work needs to be done within the field of animal PD models in the coming years. Although the concept of species barrier, i.e. the inability of some prion strains to cause disease in other species, is well described in prion disease $[29,30]$, it has yet received little attention in PD. It has been shown, however, that sequence homology between asyn and the host protein is proportional to the rate of seeding initiation, e.g., human asyn fibrils efficiently seed monomeric human asyn, while seeding of mouse asyn is inefficient (reviewed in [31]). In addition, the importance of aging and other modulatory factors including intestinal hyperpermeability, concurrent inflammation, and microbiota alterations needs to be studied in detail before firm conclusions can be drawn (Fig. 1).

Prion pathology in variant CJD exhibit peripheralto-central propagation, whereas the initial pathology in sporadic and familial CJD cases probably arises spontaneously within the brain. Thus, it is theoretically possible that synucleinopathies can similarly be divided into types either originating in the peripheral nervous system or arising spontaneously within the CNS [16]. Note that this does not necessarily imply that these synucleinopathies were contracted by exogenous agents, but can be explained by Braak's hypothesis that the nerve terminals of long, non-myelinated, hyperbranched axons are the most probable (but not only) place for the first occurrence of asyn aggregation [7].

One candidate for a peripheral-dominant subtype of PD may be those cases, in whom rapid eye movement sleep behavior disorder (RBD) presents during the prodromal phase. It has been shown that PD patients with RBD exhibit much higher frequencies of phosphorylated asyn pathology in the colon and in the skin compared to PD patients without RBD [32]. Also, idiopathic RBD patients exhibit marked pathology in the sympathetic and parasympathetic nervous system, but a relatively intact dopamine system [33]. In contrast, PD patients without RBD often have normal cardiac sympathetic innervation in early disease stages indicative of a sparing of the autonomic nervous system [34, 35]. An important research goal for the coming years will be to perform a thorough phenotypic characterization of PD subgroups using objective markers of neuronal dysfunction. It urgently needs to be clarified whether such distinct phenotypes can be explained by molecular characteristics of pathological asyn in the ENS and CNS (Fig. 1). An attractive hypothesis is that some specific post-translationally modified forms of asyn and/or assemblies (strains) could be associated with a more aggressive disease progression [36]. 


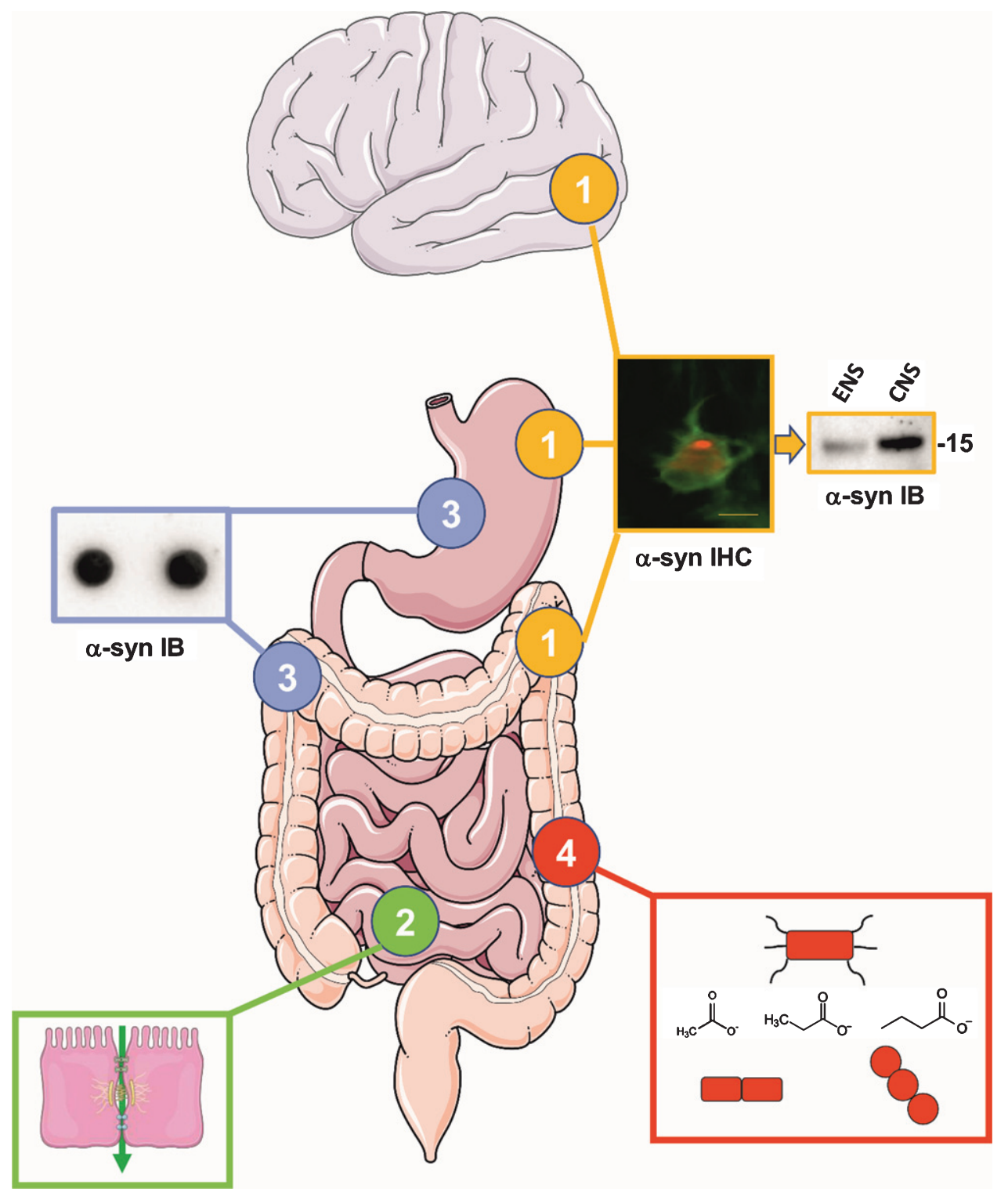

Fig. 1. The four most important issues that need to be addressed in the next 10 years regarding the gut in PD. (1) Alpha-synuclein deposits are observed in the ENS of PD patients (the microphotography shows phospho-alpha-synuclein immunostaining in the colonic myenteric plexus of a PD patient, scale bar $20 \mu \mathrm{M}$ ). However, it remains to be determined if the alpha-synuclein aggregates in the ENS are biochemically similar to the ones found in the brain as this might be critical in our understanding of the role of the gut in PD pathogenesis. The picture shows lysates from colonic biopsies (left lane, ENS) and brain samples (right lane, CNS) from two PD patients that have been analyzed by western blot using C-20R total asyn antibody. Using this simple approach, no difference is observed between the ENS and the CNS and there is therefore a critical need to perform a comprehensive inventory of synuclein forms present in the ENS from PD patients using proteomic approaches. Molecular weight in $\mathrm{kDa}$ is indicated on the right. (2) Triggering of initial alpha-synuclein aggregation in enteric nerve terminals through extrinsic factors could be facilitated by intestinal hyperpermeability. It remains to be definitely demonstrated that intestinal permeability is increased in PD. (3) Results of immunohistochemistry-based studies on alpha-synuclein deposits in the ENS of PD patients have provided conflicting results. There is therefore a critical need to develop alternative techniques to detect alpha-synuclein aggregates in the gut. The inset illustrates a dot blot from gastrointestinal biopsy lysates of a control subject, stained with Syn-1 alpha-synuclein antibody. (4) Alterations of gut microbiota composition in PD have been shown in multiple cross-sectional studies from diverse populations. It will be crucial to determine the mechanisms that connect gut microbiota and PD in large multicenter studies of prodromal and de novo PD patients as well as animal models employing multiomics approaches. Eventually, the clinical diagnostic and therapeutic potential of the gut microbiota must be determined. The inset illustrates differently shaped bacteria and the molecular structures of the SCFAs butyrate, acetate and propionate. Drawings were modified from Servier Medical Art, licensed under a Creative Commons Attribution 3.0 Unported License. 


\section{BIOMARKERS}

The observation that asyn inclusions are found in ENS of the vast majority of PD patients has led to an increasing number of immunohistochemistry-based studies aimed at developing biomarkers for disease diagnosis and progression. However, the diversity of methodology between studies, especially regarding the immunohistochemical methods used, has led to conflicting results regarding the sensitivity and specificity of gastrointestinal biopsies for the detection of asyn deposits [37]. Although several studies showed a high sensitivity of formalin-fixed paraffin embedded (FFPE) gastrointestinal biopsies for the detection of asyn inclusions in PD patients [38-41], other reports have raised concerns regarding the specificity of this approach because asyn immunoreactivity was also observed in some healthy individuals [42-45]. This lack of specificity, which likely results from technical difficulties inherent in the use of FFPE samples for the detection of asyn [46], explains why FFPE gastrointestinal biopsies are not currently used in routine clinical practice as PD biomarker. Classical biochemical approaches, such as one- and two-dimensional electrophoresis did not prove to be more efficient than immunohistochemistry for detecting aggregated asyn in gastrointestinal biopsies [47]. As a whole, these disappointing results might be explained by the low amount of aggregated/pathological asyn that is usually found in the gastrointestinal tract and especially in gastrointestinal biopsies [48]. In order to overcome this limitation, future research could take benefit from ultrasensitive techniques such as protein misfolding cyclic amplification (PMCA) and real-time quakinginduced conversion (RT-QuIC) assays, which have been recently shown to efficiently amplify aggregated asyn in cerebrospinal fluid and in formalin-fixed archived tissue $[49,50]$. In addition, there is growing evidence that pathological changes in the gut in PD are not limited to enteric neurons but also involve the enteric glial cells and the intestinal epithelial cells [51, 52], two cell types that largely outnumber enteric neurons and are easily captured by routine gastrointestinal biopsies. These observations support the hypothesis that this so-called 'neuro-glio-epithelial unit' [53] might constitute an unparalleled source of biomarkers in PD beyond the sole assessment of asyn deposits/aggregates. Possible strategies to identify new enteric markers of PD might include a joint transcriptomic and proteomic analysis of the biopsies along with the analysis of biopsy supernatant [54].
Finally, the characterization of gastrointestinal dysfunction in patients has mostly relied on scoring of subjective symptoms, which is necessarily unable to capture subclinical disease and often shows poor correlation with markers of objective dysfunction [55]. Accessible and affordable methods such as radio-opaque markers to assess gastrointestinal transit times will find more widespread use in future studies. Recently, ${ }^{11} \mathrm{C}$-donepezil PET scans have demonstrated decreased cholinergic signal in the gastrointestinal tract of both manifest and prodromal PD populations $[33,56]$. Also, once an asyn-specific PET ligand becomes available it may be possible to image not only the brain but also peripheral organs and investigate longitudinally the dual-hit hypothesis. Although expensive, such techniques will be critical to improve our understanding of PD etiopathogenesis and may have potential as progression markers in upcoming trials of disease-modification.

\section{GUT MICROBIOTA}

The human microbiota consists of bacteria, archaea, protists, fungi, their respective viruses, and human viruses. Most research has been carried out on the bacterial component of the microbiota [57]. The number of genes encoded in the gut metagenome is approximately 150 times larger than that of the human genome [58]. Evidence is accumulating that there is an intense bidirectional interaction between the gut, its microbiota, and the brain, frequently referred to as the microbiota-gut-brain-axis, which has important implications for brain health [59].

Alterations of the gut microbiota composition in PD have been revealed in multiple case-control studies from diverse populations. While there have been variations in the reported results, in PD patients an increased relative abundance of bacteria from the genera Akkermansia, Lactobacillus, and Bifidobacterium and decreased abundances of Prevotella, Faecalibacterium, and Blautia have been reproducibly shown [60-64]. For Prevotella such reduction has also been observed in RBD patients [64]. Based on the attributed functional properties of these bacteria, such alterations could affect gut barrier integrity, short-chain fatty acid (SCFA) production, and inflammation. This would be in line with reports of a leaky gut and reduced levels of SCFAs and lipopolysaccharide binding protein in PD patients $[62,65,66]$. However, it remains to be definitely proven that the gut is hyperpermeable in PD [52] (Fig. 1). Also 
with respect to SCFAs, in particular butyrate, the effects on PD pathology are not unequivocally established, since beneficial and harmful effects have been reported from PD animal and in vitro models [67-70]. An interesting link between gut microbiota and asyn pathology could be cross-seeding of amyloid pathology induced by bacterial amyloid proteins such as curli [71]. Few studies have investigated the nasal and oral microbiota in PD. While some alterations were found in the oral microbiota, two studies failed to find alterations in the nasal compartment $[64,72]$. Future research on other non-bacterial microbes such as viruses, fungi, and archaea may provide also valuable insights.

So far, human microbiome studies in PD have been carried out exclusively in medicated patients, except for one study that included also idiopathic RBD patients [64]. While the PD associated microbiome alterations have been confirmed in medication adjusted analyses, confounding effects cannot be excluded and have in fact been shown for COMT inhibitors $[60,73]$. Another potential confounder is colonic dysmotility, which may independently affect microbiota composition [60, 74]. Several microbiota studies assessed constipation symptoms using questionnaires and adjusted for reported constipation in their analyses. However, questionnaires may underestimate the prevalence of objective colonic dysfunction and thus adjustment based on these responses may be insufficient [55]. It is not known, whether the observed microbiome changes play a causal role in the development of gut pathology in PD or whether they are rather a consequence of altered gut function. Also for the observed correlations between microbiome composition and motor $[60,64]$ and non-motor symptoms $[75,76]$ causality has not been established in humans. However, observations that motor symptoms, neuroinflammation, asyn pathology, and gut motility can be modulated by manipulating the gut microbiota in transgenic asyn-overexpressing mice suggest that such causal influences are possible [68].

Whether gut microbiome alterations in $\mathrm{PD}$ are independent of medications and constipation can be addressed by comparing microbiota and objective assessments of gut function between healthy subjects and drug naïve prodromal and/or de novo patients. To establish what mechanisms link microbiota alterations and PD, such studies should employ a multiomics approach involving metagenomic, metatranscriptomic, and metabolomics analyses in combination with an assessment of host factors such as gut biopsies, permeability studies, cytokine levels and host genotype (Fig. 1). For such studies to succeed, multicenter consortia should collaborate to ensure sufficient cohort sizes and standardized methodology. Longitudinal study designs will eventually enable us to study the temporal relationship between microbiota changes, disease stages, and phenotypes. While such undertakings will be longlasting and very cost-intensive, further work in animal models may be helpful to narrow down the spectrum of potentially relevant pathways that connect microbiota and PD disease mechanisms and to test interventions.

Taken together there is good reason to envision that gut microbiota may have important implications in the future diagnostic and therapeutic landscape of PD. Analysis of the composition and/or functional aspects of the microbiome combined with clinical and genetic host factors could become a crucial element of patient phenotyping allowing more individualized treatments for PD. Using such biomarkers to select suitable patients for specifically tailored therapeutic interventions should improve odds for successful clinical trials of symptomatic or disease modifying treatments. Based on encouraging observations from RBD subjects [64], such approaches could find applications already in the prodromal phase of PD. If disease specific microbiota profiles could be established, these would be a valuable tool for the differential diagnosis of parkinsonism [77].

Therapeutic applications based on the gut microbiome are possible through a range of approaches. These include dietary interventions, application of beneficial bacteria (probiotics), substances that promote growth of beneficial bacteria (prebiotics), substances that eliminate harmful bacteria (antibiotics), and transfer of bacterial ecosystems (fecal microbiota transplantation). Furthermore, a detailed understanding of microbiome-host-interactions in PD could identify new pathways that could be targeted using more traditional pharmacological approaches. Importantly, microbiome based therapies could be effective independently of the causative role of the microbiome in PD pathogenesis. This is because the microbiome is a key regulator of neuroinflammation and could affect disease progression through modulation of microglia activity [78]. Furthermore, gut microbiota affect gut permeability and the local environment in the gut lumen and mucosa which could have an implication for the impact of environmental toxins and other PD initiating or perpetuating factors such as protein aggregation. Also, 
beneficial symptomatic effects may be achieved, as has been demonstrated in a trial showing improvement of constipation in PD patients receiving a synbiotic formulation, i.e., probiotics in combination with prebiotic fiber [79]. Finally, the microbiome may also play a role in the pharmacologic treatment of PD, as has been demonstrated for Helicobacter pylori and small intestinal bacterial overgrowth [80]. This suggests that benefits from traditional treatments of PD, such as levodopa, might be enhanced by microbiome based interventions.

\section{CONCLUSION}

In his "Essay on the shaking palsy" [81], James Parkinson noted that "Although unable to trace the connection by which a disordered state of the stomach and bowels may induce a morbid action in a part of the medulla spinalis [...] little hesitation need be employed before we determine on the probability of such occurrence." In line with his statement, our understanding and appreciation of the importance of the gut-brain connection in PD has grown rapidly in recent years. We are confident that the coming two decades of microbiome-gut-brain-axis research will see an even accelerated development in this area that will reshape our understanding of the pathogenesis of PD. While there is a hype, there is definitely also hope that this will translate into improved diagnostic and therapeutic approaches and eventually disease modifying treatments for PD patients.

\section{ACKNOWLEDGMENTS}

FS is funded by The Academy of Finland (295724, 310835), The Finnish Medical Foundation, the European Commission (TreatER), and Helsinki University Hospital (TYH2018224).

PD is funded by France Parkinson and Institut de France.

PB is funded by Jascha Foundation, Danish Parkinson's Association, Lundbeck Foundation, Novo Nordisk Foundation.

\section{CONFLICT OF INTEREST}

FS is founder and CEO of NeuroInnovation Oy, has received consulting fees from LivaNova and Illumina Ventures, lecture fees from Abbvie and Zambon, travel support from Abbvie, LivaNova, and Zambon, is member of the scientific advisory boards of Axial
Biotherapeutics and LivaNova, and is listed as inventor on the patent applications FI20145492A, PCT/ FI2015/050374, EP20150798909, and US15314240.

PD has nothing to disclose.

PB has nothing to disclose.

\section{REFERENCES}

[1] den Hartog Jager WA, Bethlem J (1960) The distribution of Lewy bodies in the central and autonomic nervous systems in idiopathic paralysis agitans. J Neurol Neurosurg Psychiatry 23, 283-290.

[2] Wakabayashi K, Takahashi H, Takeda S, Ohama E, Ikuta F (1988) Parkinson's disease: The presence of Lewy bodies in Auerbach's and Meissner's plexuses. Acta Neuropathol 76, 217-221.

[3] Beach TG, Adler CH, Sue LI, Vedders L, Lue L, White Iii CL, Akiyama H, Caviness JN, Shill HA, Sabbagh MN, Walker DG, Arizona Parkinson's Disease Consortium (2010) Multi-organ distribution of phosphorylated alpha-synuclein histopathology in subjects with Lewy body disorders. Acta Neuropathol 119, 689-702.

[4] Gelpi E, Navarro-Otano J, Tolosa E, Gaig C, Compta Y, Rey MJ, Marti MJ, Hernandez I, Valldeoriola F, Rene R, Ribalta $\mathrm{T}$ (2014) Multiple organ involvement by alpha-synuclein pathology in Lewy body disorders. Mov Disord 29, 10101018.

[5] Annerino DM, Arshad S, Taylor GM, Adler CH, Beach TG, Greene JG (2012) Parkinson's disease is not associated with gastrointestinal myenteric ganglion neuron loss. Acta Neuropathol 124, 665-680.

[6] Lebouvier T, Neunlist M, Bruley des Varannes S, Coron E, Drouard A, N'Guyen JM, Chaumette T, Tasselli M, Paillusson S, Flamand M, Galmiche JP, Damier P, Derkinderen P (2010) Colonic biopsies to assess the neuropathology of Parkinson's disease and its relationship with symptoms. PLoS One 5, e12728.

[7] Braak H, Del Tredici K, Rub U, de Vos RA, Jansen Steur EN, Braak E (2003) Staging of brain pathology related to sporadic Parkinson's disease. Neurobiol Aging 24, 197-211.

[8] Hawkes CH, Del Tredici K, Braak H (2007) Parkinson's disease: A dual-hit hypothesis. Neuropathol Appl Neurobiol 33, 599-614.

[9] Svensson E, Horvath-Puho E, Thomsen RW, Djurhuus JC, Pedersen L, Borghammer P, Sorensen HT (2015) Vagotomy and subsequent risk of Parkinson's disease. Ann Neurol 78, 522-529.

[10] Liu B, Fang F, Pedersen NL, Tillander A, Ludvigsson JF, Ekbom A, Svenningsson P, Chen H, Wirdefeldt K (2017) Vagotomy and Parkinson disease: A Swedish register-based matched-cohort study. Neurology 88, 1996-2002.

[11] Hilton D, Stephens M, Kirk L, Edwards P, Potter R, Zajicek J, Broughton E, Hagan H, Carroll C (2014) Accumulation of alpha-synuclein in the bowel of patients in the pre-clinical phase of Parkinson's disease. Acta Neuropathol 127, 235241.

[12] Stokholm MG, Danielsen EH, Hamilton-Dutoit SJ, Borghammer P (2016) Pathological alpha-synuclein in gastrointestinal tissues from prodromal Parkinson disease patients. Ann Neurol 79, 940-949.

[13] Steiner JA, Quansah E, Brundin P (2018) The concept of alpha-synuclein as a prion-like protein: Ten years after. Cell Tissue Res 373, 161-173. 
[14] Breid S, Bernis ME, Babila JT, Garza MC, Wille H, Tamguney $G$ (2016) Neuroinvasion of alpha-synuclein prionoids after intraperitoneal and intraglossal inoculation. J Virol 90, 9182-9193.

[15] Ayers JI, Brooks MM, Rutherford NJ, Howard JK, Sorrentino ZA, Riffe CJ, Giasson BI (2017) Robust central nervous system pathology in transgenic mice following peripheral injection of alpha-synuclein fibrils. J Virol 91, e02095-16.

[16] Borghammer P (2018) How does parkinson's disease begin? Perspectives on neuroanatomical pathways, prions, and histology. Mov Disord 33, 48-57.

[17] Lionnet A, Leclair-Visonneau L, Neunlist M, Murayama S, Takao M, Adler CH, Derkinderen P, Beach TG (2018) Does Parkinson's disease start in the gut? Acta Neuropathol 135, 1-12.

[18] Adler CH, Beach TG (2016) Neuropathological basis of nonmotor manifestations of Parkinson's disease. Mov Disord 31, 1114-1119.

[19] Haik S, Faucheux BA, Sazdovitch V, Privat N, Kemeny JL, Perret-Liaudet A, Hauw JJ (2003) The sympathetic nervous system is involved in variant Creutzfeldt-Jakob disease. Nat Med 9, 1121-1123.

[20] Herzog C, Sales N, Etchegaray N, Charbonnier A, Freire S, Dormont D, Deslys JP, Lasmezas CI (2004) Tissue distribution of bovine spongiform encephalopathy agent in primates after intravenous or oral infection. Lancet 363, $422-428$.

[21] van Keulen LJ, Vromans ME, Dolstra CH, Bossers A, van Zijderveld FG (2008) Pathogenesis of bovine spongiform encephalopathy in sheep. Arch Virol 153, 445-453.

[22] Hill AF, Butterworth RJ, Joiner S, Jackson G, Rossor MN, Thomas DJ, Frosh A, Tolley N, Bell JE, Spencer M, King A, Al-Sarraj S, Ironside JW, Lantos PL, Collinge J (1999) Investigation of variant Creutzfeldt-Jakob disease and other human prion diseases with tonsil biopsy samples. Lancet 353, 183-189.

[23] Wadsworth JD, Joiner S, Hill AF, Campbell TA, Desbruslais M, Luthert PJ, Collinge J (2001) Tissue distribution of protease resistant prion protein in variant Creutzfeldt-Jakob disease using a highly sensitive immunoblotting assay. Lancet 358, 171-180.

[24] Collinge J, Clarke AR (2007) A general model of prion strains and their pathogenicity. Science 318, 930-936.

[25] Corbille AG, Neunlist M, Derkinderen P (2016) Crosslinking for the analysis of alpha-synuclein in the enteric nervous system. J Neurochem 139, 839-847.

[26] Recasens A, Carballo-Carbajal I, Parent A, Bove J, Gelpi E, Tolosa E, Vila M (2018) Lack of pathogenic potential of peripheral alpha-synuclein aggregates from Parkinson's disease patients. Acta Neuropathol Commun 6, 8.

[27] Anderson JP, Walker DE, Goldstein JM, de Laat R, Banducci K, Caccavello RJ, Barbour R, Huang J, Kling K, Lee M, Diep L, Keim PS, Shen X, Chataway T, Schlossmacher MG, Seubert P, Schenk D, Sinha S, Gai WP, Chilcote TJ (2006) Phosphorylation of Ser-129 is the dominant pathological modification of alpha-synuclein in familial and sporadic Lewy body disease. J Biol Chem 281, 29739-29752.

[28] Rasmussen J, Mahler J, Beschorner N, Kaeser SA, Hasler LM, Baumann F, Nystrom S, Portelius E, Blennow K, Lashley T, Fox NC, Sepulveda-Falla D, Glatzel M, Oblak AL, Ghetti B, Nilsson KPR, Hammarstrom P, Staufenbiel M, Walker LC, Jucker M (2017) Amyloid polymorphisms constitute distinct clouds of conformational variants in different etiological subtypes of Alzheimer's disease. Proc Natl Acad Sci U S A 114, 13018-13023.

[29] Collinge J, Palmer MS, Sidle KC, Hill AF, Gowland I, Meads J, Asante E, Bradley R, Doey LJ, Lantos PL (1995) Unaltered susceptibility to BSE in transgenic mice expressing human prion protein. Nature 378, 779-783.

[30] Hill AF, Desbruslais M, Joiner S, Sidle KC, Gowland I, Collinge J, Doey LJ, Lantos P (1997) The same prion strain causes vCJD and BSE. Nature 389, 448-50, 526.

[31] Killinger BA, Labrie V (2017) Vertebrate food products as a potential source of prion-like alpha-synuclein. NPJ Parkinsons Dis 3, 33.

[32] Leclair-Visonneau L, Clairembault T, Coron E, Le Dily S, Vavasseur F, Dalichampt M, Pereon Y, Neunlist M, Derkinderen P (2017) REM sleep behavior disorder is related to enteric neuropathology in Parkinson disease. $\mathrm{Neu}$ rology 89, 1612-1618.

[33] Knudsen K, Fedorova TD, Hansen AK, Sommerauer M, Otto M, Svendsen KB, Nahimi A, Stokholm MG, Pavese N, Beier CP, Brooks DJ, Borghammer P (2018) In-vivo staging of pathology in REM sleep behaviour disorder: A multimodality imaging case-control study. Lancet Neurol 17, 618-628.

[34] Nomura T, Inoue Y, Hogl B, Uemura Y, Kitayama M, Abe T, Miyoshi H, Nakashima K (2010) Relationship between (123)I-MIBG scintigrams and REM sleep behavior disorder in Parkinson's disease. Parkinsonism Relat Disord 16, 683685.

[35] Kim JS, Park HE, Oh YS, Lee SH, Park JW, Son BC, Lee KS (2016) Orthostatic hypotension and cardiac sympathetic denervation in Parkinson disease patients with REM sleep behavioral disorder. J Neurol Sci 362, 59-63.

[36] Peelaerts W, Bousset L, Van der Perren A, Moskalyuk A, Pulizzi R, Giugliano M, Van den Haute C, Melki R, Baekelandt V (2015) alpha-Synuclein strains cause distinct synucleinopathies after local and systemic administration. Nature 522, 340-344.

[37] Corbille AG, Clairembault T, Coron E, Leclair-Visonneau L, Preterre C, Neunlist M, Derkinderen P (2016) What a gastrointestinal biopsy can tell us about Parkinson's disease? Neurogastroenterol Motil 28, 966-974.

[38] Shannon KM, Keshavarzian A, Mutlu E, Dodiya HB, Daian D, Jaglin JA, Kordower JH (2012) Alpha-synuclein in colonic submucosa in early untreated Parkinson's disease. Mov Disord 27, 709-715.

[39] Sanchez-Ferro A, Rabano A, Catalan MJ, RodriguezValcarcel FC, Fernandez Diez S, Herreros-Rodriguez J, Garcia-Cobos E, Alvarez-Santullano MM, LopezManzanares L, Mosqueira AJ, Vela Desojo L, Lopez-Lozano JJ, Lopez-Valdes E, Sanchez-Sanchez $\mathrm{R}$, Molina-Arjona JA (2015) In vivo gastric detection of alpha-synuclein inclusions in Parkinson's disease. Mov Disord 30, 517-524.

[40] Aldecoa I, Navarro-Otano J, Stefanova N, Sprenger FS, Seppi K, Poewe W, Cuatrecasas M, Valldeoriola F, Gelpi E, Tolosa E (2015) Alpha-synuclein immunoreactivity patterns in the enteric nervous system. Neurosci Lett $\mathbf{6 0 2}$, 145-149.

[41] Yan F, Chen Y, Li M, Wang Y, Zhang W, Chen X, Ye Q (2018) Gastrointestinal nervous system alpha-synuclein as a potential biomarker of Parkinson disease. Medicine (Baltimore) 97, e11337.

[42] Chung SJ, Kim J, Lee HJ, Ryu HS, Kim K, Lee JH, Jung KW, Kim MJ, Kim MJ, Kim YJ, Yun SC, Lee JY, Hong SM, Myung SJ (2016) Alpha-synuclein in gastric and colonic 
mucosa in Parkinson's disease: Limited role as a biomarker. Mov Disord 31, 241-249.

[43] Visanji NP, Marras C, Kern DS, Al Dakheel A, Gao A, Liu LW, Lang AE, Hazrati LN (2015) Colonic mucosal a-synuclein lacks specificity as a biomarker for Parkinson disease. Neurology 84, 609-616.

[44] Ruffmann C, Bengoa-Vergniory N, Poggiolini I, Ritchie D, Hu MT, Alegre-Abarrategui J, Parkkinen L (2018) Detection of alpha-synuclein conformational variants from gastro-intestinal biopsy tissue as a potential biomarker for Parkinson's disease. Neuropathol Appl Neurobiol. doi: 10.1111/nan. 12486

[45] Shin C, Park SH, Yun JY, Shin JH, Yang HK, Lee HJ, Kong SH, Suh YS, Shen G, Kim Y, Kim HJ, Jeon B (2017) Fundamental limit of alpha-synuclein pathology in gastrointestinal biopsy as a pathologic biomarker of Parkinson's disease: Comparison with surgical specimens. Parkinsonism Relat Disord 44, 73-78.

[46] Shin C, Park SH, Yun JY, Shin JH, Yang HK, Lee HJ, Kong SH, Suh YS, Kim HJ, Jeon B (2018) Alpha-synuclein staining in non-neural structures of the gastrointestinal tract is non-specific in Parkinson disease. Parkinsonism Relat Disord. doi: 10.1016/j.parkreldis.2018.09.026

[47] Corbille AG, Preterre C, Rolli-Derkinderen M, Coron E, Neunlist M, Lebouvier T, Derkinderen P (2017) Biochemical analysis of alpha-synuclein extracted from control and Parkinson's disease colonic biopsies. Neurosci Lett 641, 81-86.

[48] Beach TG, Corbille AG, Letournel F, Kordower JH, Kremer T, Munoz DG, Intorcia A, Hentz J, Adler CH, Sue LI, Walker J, Serrano G, Derkinderen P (2016) Multicenter assessment of immunohistochemical methods for pathological alphasynuclein in sigmoid colon of autopsied Parkinson's disease and control subjects. J Parkinsons Dis 6, 761-770.

[49] Shahnawaz M, Tokuda T, Waragai M, Mendez N, Ishii R, Trenkwalder C, Mollenhauer B, Soto C (2017) Development of a biochemical diagnosis of Parkinson disease by detection of alpha-synuclein misfolded aggregates in cerebrospinal fluid. JAMA Neurol 74, 163-172.

[50] Becker K, Wang X, Vander Stel K, Chu Y, Kordower J, Ma J (2018) Detecting alpha synuclein seeding activity in formaldehyde-fixed MSA patient tissue by PMCA. Mol Neurobiol 55, 8728-8737.

[51] Clairembault T, Kamphuis W, Leclair-Visonneau L, RolliDerkinderen M, Coron E, Neunlist M, Hol EM, Derkinderen $\mathrm{P}$ (2014) Enteric GFAP expression and phosphorylation in Parkinson's disease. J Neurochem 130, 805-815.

[52] Clairembault T, Leclair-Visonneau L, Coron E, Bourreille A, Le Dily S, Vavasseur F, Heymann MF, Neunlist M, Derkinderen P (2015) Structural alterations of the intestinal epithelial barrier in Parkinson's disease. Acta Neuropathol Commun 3, 12.

[53] Neunlist M, Van Landeghem L, Mahe MM, Derkinderen P, des Varannes SB, Rolli-Derkinderen M (2013) The digestive neuronal-glial-epithelial unit: A new actor in gut health and disease. Nat Rev Gastroenterol Hepatol 10, 90-100.

[54] Dussik CM, Hockley M, Grozic A, Kaneko I, Zhang L, Sabir MS, Park J, Wang J, Nickerson CA, Yale SH, Rall CJ, Foxx-Orenstein AE, Borror CM, Sandrin TR, Jurutka PW (2018) Gene expression profiling and assessment of vitamin $\mathrm{D}$ and serotonin pathway variations in patients with irritable bowel syndrome. J Neurogastroenterol Motil 24, 96-106.

[55] Knudsen K, Fedorova TD, Bekker AC, Iversen P, Ostergaard K, Krogh K, Borghammer P (2017) Objective colonic dysfunction is far more prevalent than subjective constipation in Parkinson's disease: A colon transit and volume study. J Parkinsons Dis 7, 359-367.

[56] Fedorova TD, Seidelin LB, Knudsen K, Schacht AC, Geday J, Pavese N, Brooks DJ, Borghammer P (2017) Decreased intestinal acetylcholinesterase in early Parkinson disease: An (11)C-donepezil PET study. Neurology 88, 775-781.

[57] Aho VT, Pereira PA, Haahtela T, Pawankar R, Auvinen P, Koskinen K (2015) The microbiome of the human lower airways: A next generation sequencing perspective. World Allergy Organ J 8, 23.

[58] Qin J, Li R, Raes J, Arumugam M, Burgdorf KS, Manichanh C, Nielsen T, Pons N, Levenez F, Yamada T, Mende DR, Li J, Xu J, Li S, Li D, Cao J, Wang B, Liang H, Zheng H, Xie Y, Tap J, Lepage P, Bertalan M, Batto JM, Hansen T, Le Paslier D, Linneberg A, Nielsen HB, Pelletier E, Renault P, Sicheritz-Ponten T, Turner K, Zhu H, Yu C, Li S, Jian M, Zhou Y, Li Y, Zhang X, Li S, Qin N, Yang H, Wang J, Brunak S, Dore J, Guarner F, Kristiansen K, Pedersen O, Parkhill J, Weissenbach J, MetaHIT Consortium, Bork P, Ehrlich SD, Wang J (2010) A human gut microbial gene catalogue established by metagenomic sequencing. Nature 464, 59-65.

[59] Cryan JF, Dinan TG (2012) Mind-altering microorganisms: The impact of the gut microbiota on brain and behaviour. Nat Rev Neurosci 13, 701-712.

[60] Scheperjans F, Aho V, Pereira PA, Koskinen K, Paulin L, Pekkonen E, Haapaniemi E, Kaakkola S, Eerola-Rautio J, Pohja M, Kinnunen E, Murros K, Auvinen P (2015) Gut microbiota are related to Parkinson's disease and clinical phenotype. Mov Disord 30, 350-358.

[61] Keshavarzian A, Green SJ, Engen PA, Voigt RM, Naqib A, Forsyth CB, Mutlu E, Shannon KM (2015) Colonic bacterial composition in Parkinson's disease. Mov Disord 30, 13511360.

[62] Unger MM, Spiegel J, Dillmann KU, Grundmann D, Philippeit H, Burmann J, Fassbender K, Schwiertz A, Schafer KH (2016) Short chain fatty acids and gut microbiota differ between patients with Parkinson's disease and age-matched controls. Parkinsonism Relat Disord 32, 6672.

[63] Bedarf JR, Hildebrand F, Coelho LP, Sunagawa S, Bahram M, Goeser F, Bork P, Wullner U (2017) Functional implications of microbial and viral gut metagenome changes in early stage L-DOPA-naive Parkinson's disease patients. Genome Med 9, 39. Erratum in Genome Med 2017; 29, 61.

[64] Heintz-Buschart A, Pandey U, Wicke T, Sixel-Doring F, Janzen A, Sittig-Wiegand E, Trenkwalder C, Oertel WH, Mollenhauer B, Wilmes P (2018) The nasal and gut microbiome in Parkinson's disease and idiopathic rapid eye movement sleep behavior disorder. Mov Disord 33, 88-98.

[65] Forsyth CB, Shannon KM, Kordower JH, Voigt RM, Shaikh M, Jaglin JA, Estes JD, Dodiya HB, Keshavarzian A (2011) Increased intestinal permeability correlates with sigmoid mucosa alpha-synuclein staining and endotoxin exposure markers in early Parkinson's disease. PLoS One 6, e28032.

[66] Hasegawa S, Goto S, Tsuji H, Okuno T, Asahara T, Nomoto K, Shibata A, Fujisawa Y, Minato T, Okamoto A, Ohno K, Hirayama M (2015) Intestinal dysbiosis and lowered serum lipopolysaccharide-binding protein in Parkinson's disease. PLoS One 10, e0142164.

[67] St Laurent R, O’Brien LM, Ahmad ST (2013) Sodium butyrate improves locomotor impairment and early mortality in a rotenone-induced Drosophila model of Parkinson's disease. Neuroscience 246, 382-390. 
[68] Sampson TR, Debelius JW, Thron T, Janssen S, Shastri GG, Ilhan ZE, Challis C, Schretter CE, Rocha S, Gradinaru V, Chesselet MF, Keshavarzian A, Shannon KM, KrajmalnikBrown R, Wittung-Stafshede P, Knight R, Mazmanian SK (2016) Gut microbiota regulate motor deficits and neuroinflammation in a model of Parkinson's disease. Cell 167, 1469-1480.e12.

[69] Liu J, Wang F, Liu S, Du J, Hu X, Xiong J, Fang R, Chen W, Sun J (2017) Sodium butyrate exerts protective effect against Parkinson's disease in mice via stimulation of glucagon like peptide-1. J Neurol Sci 381, 176-181.

[70] Paiva I, Pinho R, Pavlou MA, Hennion M, Wales P, Schutz AL, Rajput A, Szego EM, Kerimoglu C, Gerhardt E, Rego AC, Fischer A, Bonn S, Outeiro TF (2017) Sodium butyrate rescues dopaminergic cells from alpha-synuclein-induced transcriptional deregulation and DNA damage. Hum $\mathrm{Mol}$ Genet 26, 2231-2246.

[71] Chen SG, Stribinskis V, Rane MJ, Demuth DR, Gozal E, Roberts AM, Jagadapillai R, Liu R, Choe K, Shivakumar B, Son F, Jin S, Kerber R, Adame A, Masliah E, Friedland RP (2016) Exposure to the functional bacterial amyloid protein curli enhances alpha-synuclein aggregation in aged Fischer 344 rats and Caenorhabditis elegans. Sci Rep 6, 34477.

[72] Pereira PAB, Aho VTE, Paulin L, Pekkonen E, Auvinen P, Scheperjans F (2017) Oral and nasal microbiota in Parkinson's disease. Parkinsonism Relat Disord 38, 61-67.

[73] Hill-Burns EM, Debelius JW, Morton JT, Wissemann WT, Lewis MR, Wallen ZD, Peddada SD, Factor SA, Molho E, Zabetian CP, Knight R, Payami H (2017) Parkinson's disease and Parkinson's disease medications have distinct signatures of the gut microbiome. Mov Disord 32, 739-749.

[74] Vandeputte D, Falony G, Vieira-Silva S, Tito RY, Joossens M, Raes J (2016) Stool consistency is strongly associated with gut microbiota richness and composition, enterotypes and bacterial growth rates. Gut $\mathbf{6 5}, 57-62$.
[75] Mertsalmi TH, Aho VTE, Pereira PAB, Paulin L, Pekkonen E, Auvinen P, Scheperjans F (2017) More than constipation bowel symptoms in Parkinson's disease and their connection to gut microbiota. Eur J Neurol 24, 1375-1383.

[76] Alifirova VM, Zhukova NG, Zhukova IA, Mironova YS, Petrov VA, Izhboldina OP, Titova MA, Latypova AV, Nikitina MA, Dorofeeva YB, Saltykova IV, Tyakht AV, Kostryukova ES, Sazonov AE (2016) Correlation between emotional-affective disorders and gut microbiota composition in patients with Parkinson's disease. Vestn Ross Akad Med Nauk 71, 427-435.

[77] Engen PA, Dodiya HB, Naqib A, Forsyth CB, Green SJ, Voigt RM, Kordower JH, Mutlu EA, Shannon KM, Keshavarzian A (2017) The potential role of gut-derived inflammation in multiple system atrophy. J Parkinsons Dis 7, 331-346.

[78] Erny D, Hrabe de Angelis AL, Jaitin D, Wieghofer P, Staszewski O, David E, Keren-Shaul H, Mahlakoiv T, Jakobshagen K, Buch T, Schwierzeck V, Utermohlen O, Chun E, Garrett WS, McCoy KD, Diefenbach A, Staeheli P, Stecher B, Amit I, Prinz M (2015) Host microbiota constantly control maturation and function of microglia in the CNS. Nat Neurosci 18, 965-977.

[79] Barichella M, Pacchetti C, Bolliri C, Cassani E, Iorio L, Pusani C, Pinelli G, Privitera G, Cesari I, Faierman SA, Caccialanza R, Pezzoli G, Cereda E (2016) Probiotics and prebiotic fiber for constipation associated with Parkinson disease: An RCT. Neurology 87, 1274-1280.

[80] Fasano A, Bove F, Gabrielli M, Petracca M, Zocco MA, Ragazzoni E, Barbaro F, Piano C, Fortuna S, Tortora A, Di Giacopo R, Campanale M, Gigante G, Lauritano EC, Navarra P, Marconi S, Gasbarrini A, Bentivoglio AR (2013) The role of small intestinal bacterial overgrowth in Parkinson's disease. Mov Disord 28, 1241-1249.

[81] Parkinson J (1817) An essay on the shaking palsy. 